\title{
Canadian Critical Care Society clinical practice guideline: The use of vasopressin and vasopressin analogues in critically ill adults with distributive shock
}

\section{Recommandation de pratique clinique de la Société canadienne de soins intensifs: utilisation de vasopressine et d'analogues de la vasopressine chez l'adulte en état critique souffrant de choc distributif}

\begin{abstract}
Kimia Honarmand, MSc, MD - Kevin John Um, MD - Emilie P. Belley-Côté, MD PhD • Waleed Alhazzani, MD, MSc · Chris Farley, BHSc, MScPT - Shannon M. Fernando, MD, MSc · Kirsten Fiest, PhD • Donna Grey • Edita Hajdini, RN • Margaret Herridge, MD, MSc • Carmen Hrymak, MD • Morten Hylander Møller, MD, PhD - Salmaan Kanji, PharmD • François Lamontagne, MD, MSc • François Lauzier, MD, MSc · Sangeeta Mehta, MD • Bojan Paunovic, MD • Rohit Singal, MD, MSc • Jennifer Ly Tsang, MD, PhD • Christine Wynne, BSc, BScPhm, ACPR - Bram Rochwerg, MD, MSc
\end{abstract}

Received: 25 July 2019/Revised: 30 September 2019/Accepted: 4 October 2019/Published online: 3 December 2019

(C) Canadian Anesthesiologists' Society 2019

Abstract

Purpose Hemodynamic management of adults with distributive shock often includes the use of catecholamine-based vasoconstricting medications. It is

Electronic supplementary material The online version of this article (https://doi.org/10.1007/s12630-019-01546-x) contains supplementary material, which is available to authorized users.

K. Honarmand, MSc, MD

Division of Critical Care, Department of Medicine, Western

University, London, ON, Canada

Department of Health Research Methods, Evidence, and Impact, McMaster University, Hamilton, ON, Canada

K. J. Um, MD · E. P. Belley-Côté, MD PhD

Department of Medicine, McMaster University, Hamilton, ON, Canada

W. Alhazzani, MD, MSc

Department of Health Research Methods, Evidence, and Impact,

McMaster University, Hamilton, ON, Canada

Department of Medicine, McMaster University, Hamilton, ON, Canada

C. Farley, BHSc, MScPT · C. Wynne, BSc, BScPhm, ACPR

Hamilton Health Sciences Centre, Hamilton, ON, Canada unclear whether adding vasopressin or vasopressin analogues to catecholamine therapy is beneficial in the management of patients with distributive shock. The purpose of this guideline was to develop an evidencebased recommendation regarding the addition of vasopressin to catecholamine vasopressors in the management of adults with distributive shock.

S. M. Fernando, MD, MSc

Division of Critical Care, Department of Medicine and

Department of Emergency Medicine, University of Ottawa,

Ottawa, ON, Canada

K. Fiest, $\mathrm{PhD}$

Department of Critical Care Medicine, Cumming School of Medicine, University of Calgary, Calgary, AB, Canada

D. Grey $\cdot$ E. Hajdini, RN

School of Nursing, McMaster University, Hamilton, ON, Canada

M. Herridge, MD, MSc

Department of Medicine, Toronto General Hospital/University Health Network, and Interdepartmental Division of Critical Care Medicine, University of Toronto, Toronto, ON, Canada

C. Hrymak, MD

Section of Critical Care, Department of Medicine, and Department of Emergency Medicine, University of Manitoba, Winnipeg, MB, Canada 
Methods We summarized the evidence informing this recommendation by updating a recently published metaanalysis. Then, a multidisciplinary panel from the Canadian Critical Care Society developed the recommendation using Grading of Recommendations, Assessment, Development, and Evaluation (GRADE) methodology.

Results The updated systematic review identified 25 randomized controlled trials including a total of 3,737 patients with distributive shock. Compared with catecholamine therapy alone, the addition of vasopressin or its analogues was associated with a reduced risk of mortality (relative risk [RR], 0.91; 95\% confidence interval [CI], 0.85 to 0.99; low certainty), reduced risk of atrial fibrillation (RR, 0.77; 95\% CI, 0.67 to 0.88; high certainty), and increased risk of digital ischemia (RR, 2.56; 95\% CI, 1.24 to 5.25; moderate certainty).

Conclusions After considering certainty in the evidence, values and preferences, cost, and other factors, the expert guideline panel suggests using vasopressin or vasopressin analogues in addition to catecholamines over catecholamine vasopressors alone for the management of distributive shock (conditional recommendation, low certainty evidence).

\section{H. Møller, MD, PhD}

Department of Intensive Care, Copenhagen University Hospital, Rigshospitalet, Denmark

Centre for Research in Intensive Care, Copenhagen, Denmark

\section{S. Kanji, PharmD}

Department of Pharmacy, The Ottawa Hospital and Clinical Epidemiology Program, The Ottawa Hospital Research Institute, Ottawa, ON, Canada

F. Lamontagne, MD, MSc

Department of Medicine, Université de Sherbrooke and Centre de recherche du CHU de Sherbrooke, Sherbrooke, QC, Canada

F. Lauzier, MD, MSc

Department of Medicine and Department of Anesthesiology \& Critical Care and Trauma - Emergency - Critical Care Medicine, Population Health and Optimal Health Practices Research Unit, CHU de Québec, Université Laval Research Centre, Université Laval, Quebec, QC, Canada

\section{S. Mehta, MD}

Department of Medicine, Sinai Health System and Interdepartmental Division of Critical Care Medicine, University of Toronto, Toronto, ON, Canada

B. Paunovic, MD

Department of Internal Medicine, Section of Critical Care, Max Rady College of Medicine, University of Manitoba, Winnipeg, MB, Canada

\section{Résumé}

Objectif La prise en charge hémodynamique des adultes atteints de choc distributif comprend souvent le recours à des agents vasoconstricteurs à base de catécholamines. Nous ne savons pas si l'ajout de vasopressine ou d'analogues de la vasopressine au traitement de catécholamines est bénéfique pour la prise en charge des patients atteints de choc distributif. L'objectif de cette ligne directrice était de mettre au point une recommandation fondée sur des données probantes concernant l'ajout de vasopressine aux vasopresseurs à base de catécholamines pour la prise en charge des adultes touchés par un choc distributif.

Méthode Nous avons résumé les données probantes sur lesquelles se fonde cette recommandation en mettant à jour une méta-analyse publiée récemment. Par la suite, un panel multidisciplinaire de la Société canadienne de soins intensifs a mis au point une recommandation en se fondant sur la méthodologie GRADE (Grading of Recommendations, Assessment, Development, and Evaluation).

Résultats La revue systématique mise à jour a identifié 25 études randomisées contrôlées, comptant un total de 3737 patients atteints de choc distributif. Par rapport à un traitement à base de catécholamines seulement, l'ajout de vasopressine ou de ses analogues a été associé à une réduction du risque de mortalité (risque relatif [RR], 0,91; intervalle de confiance [IC] $95 \%$, 0,85 à 0,99; certitude

R. Singal, MD, MSc

CVT Associates, Vancouver Island Health Authority, Victoria, BC, Canada

\section{J. L. Tsang, MD, PhD}

Department of Medicine, McMaster University, Hamilton, ON, Canada

Department of Medicine, Niagara Health, Niagara, ON, Canada

B. Rochwerg, MD, MSc $(\bowtie)$

Department of Health Research Methods, Evidence, and Impact, McMaster University, Hamilton, ON, Canada

e-mail: rochwerg@mcmaster.ca

Department of Medicine, McMaster University, Hamilton, ON, Canada

Department of Medicine, Faculty of Health Sciences, Juravinski Hospital, 711 Concession Street, Hamilton, ON L8V 1C3, Canada 
faible), une réduction du risque de fibrillation auriculaire (RR, 0,77; IC $95 \%, 0,67$ à 0,88; certitude forte), et une augmentation du risque d'ischémie digitale ( $R R, 2,56$; IC $95 \%, 1,24$ à 5,25; certitude modérée).

Conclusion Après avoir examiné le niveau de certitude des données probantes, les valeurs et préférences, le coût et d'autres facteurs, le panel d'experts pour l'élaboration des directives suggère d'utiliser des vasopressines ou des analogues de la vasopressine en plus des catécholamines, plutôt que seulement des vasopresseurs à base de catécholamines, pour la prise en charge du choc distributif (recommandation conditionnelle, données probantes de certitude faible).

This recommendation was developed by the Canadian Critical Care Society (CCCS) according to standards for trustworthy guidelines. ${ }^{1,2}$ Target users of this guideline are clinicians who manage adult patients with distributive shock. The electronic supplemental material includes the outcome rankings by panel members and relevant forest plots (see supplemental material). The recommendation and decision aids can also be found within MAGICapp at: https://app.magicapp.org/app\#/guideline/4012.

\section{Background}

Distributive shock is a condition in which systemic vasodilation results in decreased blood pressure and organ perfusion potentially leading to organ damage, failure, and death. Although distributive shock occurs most commonly with sepsis, it may be associated with other conditions such as anaphylaxis and following cardiac surgery. ${ }^{3,4}$ In conjunction with fluid therapy, hemodynamic support relies on the use of catecholamine-based vasoconstricting medications, either as a sole therapy or in combination with other vasopressors.

A recent clinical practice guideline recommended against targeting a higher mean arterial blood pressure (MAP) of $75-85 \mathrm{mmHg}$ compared with a lower MAP target of $60-70 \mathrm{mmHg}$ in adult critically ill patients with hypotension and requiring vasopressors (conditional recommendation). ${ }^{5}$ The optimal use of various vasopressor agents is less clear. While catecholaminebased vasoconstrictors can be lifesaving, they have been associated with adverse events such as an increased risk of atrial fibrillation and mortality. ${ }^{6}$ New-onset atrial fibrillation in intensive care unit (ICU) patients has been associated with an increased risk of stroke and mortality. ${ }^{7}-9$
Vasopressin deficiency may play a significant role in vasoplegia, a condition referring to uncontrolled vasodilation that occurs in the context of distributive shock. ${ }^{10}$ Vasopressin, an endogenous peptide hormone, and vasopressin analogues (such as terlipressin and pituitrin) are non-catecholamine vasoconstrictors that may be used in combination with catecholamine-based vasopressors to manage distributive shock. ${ }^{11,12}$ Despite a number of randomized-controlled trials (RCTs) examining the role of vasopressin in this setting and the 2016 Surviving Sepsis Guidelines recommending vasopressin for raising mean arterial pressure to target or decreasing norepinephrine dosage, ${ }^{13}$ it is not universally used in clinical practice. For example, in the Adjunctive Glucocorticoid Therapy in Patients with Septic Shock (ADRENAL) RCT, which randomized 3,800 mechanically ventilated adult patients with septic shock to hydrocortisone or placebo, only $16 \%$ received vasopressin. ${ }^{14}$

A previous systematic review and meta-analysis of studies found that the addition of vasopressin or analogues to catecholamines in adults with distributive shock was associated with a decreased incidence of atrial fibrillation but an increased incidence of digital ischemia. ${ }^{6}$ In light of the publication of more recent studies examining the effect of adding vasopressin or vasopressin analogues to catecholamine therapy in distributive shock, ${ }^{15}{ }^{17}$ we sought to update the previous meta-analysis and to develop a clinical practice guideline on the role of vasopressin and vasopressin analogues added to catecholamine therapy in the management of adult patients with distributive shock.

\section{PICO question}

In adult patients with distributive shock, should we use vasopressin or vasopressin analogues in addition to catecholamine vasopressors vs catecholamine vasopressors alone?

\section{Methods}

Panel composition: We sought diversity in the selection of panel members to incorporate a wide range of perspectives. The panel included a family partner (family member of an ICU survivor), critical care specialists (representing both Canadian community and academic practices, an international critical care expert, a cardiac surgeon/critical care physician, and an expert in longterm patient outcomes), critical care pharmacists, a critical care nurse, a physiotherapist, and a health research epidemiologist/knowledge translation expert. The panel 
adhered to the standards for trustworthy guidelines ${ }^{1,2}$ using the Grades of Recommendation, Assessment, Development, and Evaluation (GRADE) approach. ${ }^{18}$ External peer review of the guideline was accomplished through peer review at the time of journal manuscript submission.

\section{Conflicts of interest}

All invited panel members completed a declaration form reporting all potential conflicts of interest. ${ }^{19}$ The steering committee (B.R., K.H., E.B.C.) reviewed all forms; one individual with relevant conflicts of interest was subsequently excluded from the panel.

\section{Outcome prioritization}

Panel members, including the family partner, were invited to independently rate the importance of various outcomes from the patient's perspective on a numeric scale from 1 (not important) to 9 (critical). Panel members were asked to suggest additional outcomes they believed to be important to patients. In keeping with GRADE, outcomes that received a panel mean score $\geq 7$ were considered critical for deciding the strength and direction of the recommendation. The panel acknowledged there may be other outcomes that are important to patients that were not considered in generating this recommendation (see Electronic Supplementary Material [ESM] eTable 1).

Systematic review and evaluation of the evidence

To inform the development of this guideline, the systematic review team (E.B.C., K.J.U., W.A., F.L.A.M.) updated a recently published systematic review and metaanalysis of RCTs that addressed the question of interest: "In adult patients with distributive shock, should we use vasopressin or vasopressin analogues in addition to catecholamine vasopressors vs catecholamine vasopressors alone?" 6 The search strategy, screening, data extraction, risk of bias assessment, and analysis were the same as those of the original meta-analysis published by McIntyre et $a l .{ }^{6}$ and is included in ESM eTable 2. We used the GRADE approach to evaluate the certainty in evidence identified in the systematic review. ${ }^{18}$

Recommendation development

In generating this recommendation, the panel used the GRADE approach (as shown in ESM eTable 3) and considered the benefits and harms of the addition of vasopressin or vasopressin analogues to catecholamine therapy $v s$ catecholamine therapy alone in the treatment of distributive shock. The panel also considered the relative importance of each of these outcomes to patients, certainty in this evidence, values and preferences by patients, costs, acceptability to patients and clinicians, and feasibility of each approach. ${ }^{18}$ If new relevant research related to this topic is published, this panel will reconvene to determine whether the recommendation should be revised.

Role of the sponsor

The CCCS provided videoconferencing software and endorsement but had no other involvement in developing the guideline.

Characteristics of included studies

The updated literature search identified 25 RCTs comparing the use of vasopressin or vasopressin analogues in addition to catecholamine vasopressors vs catecholamines alone in a total of 3,737 patients [mean (standard deviation) age, 61 (14) yr; 43\% women] with distributive shock. ${ }^{15}{ }^{17,20}{ }^{41}$ Twenty-four studies included patients with septic shock and one included patients with vasoplegia following cardiac surgery. Nine studies were double-blinded. . $^{15,24,29,30,34,36,37,39,41}$ Patients in the intervention arm received vasopressin in 13 studies, ${ }^{16,23,24,27,28,30,33}{ }^{37,39}$ terlipressin in 11 studies, ${ }^{15,20}{ }^{22,25,26,32,35,38,40}$ and selepressin ${ }^{41}$ and pituitrin $^{31}$ in one trial each. The range of vasopressin dosing was $0.68-2.75 \mathrm{U} \cdot \mathrm{hr}^{-1}$, and terlipressin 0.054$0.165 \mathrm{mg} \cdot \mathrm{hr}^{-1}$ (ESM eTable 4 and eFig. 1). Table 1 provides an overview of the evidence, including the benefits and harms and our certainty in the evidence for each outcome.

\section{Recommendation}

We suggest using vasopressin or vasopressin analogues in addition to catecholamines over catecholamine vasopressors alone for the management of distributive shock (conditional recommendation, low certainty evidence).

Rationale for the recommendation

Our conditional recommendation for the use of vasopressin in addition to catecholamines in distributive shock is based on the certainty in the evidence, values and preferences, cost, and other factors that inform recommendations. ESM eTable $3 \mathrm{~b}$ outlines the implications of various GRADE recommendations for patients, clinicians, and policy makers. 


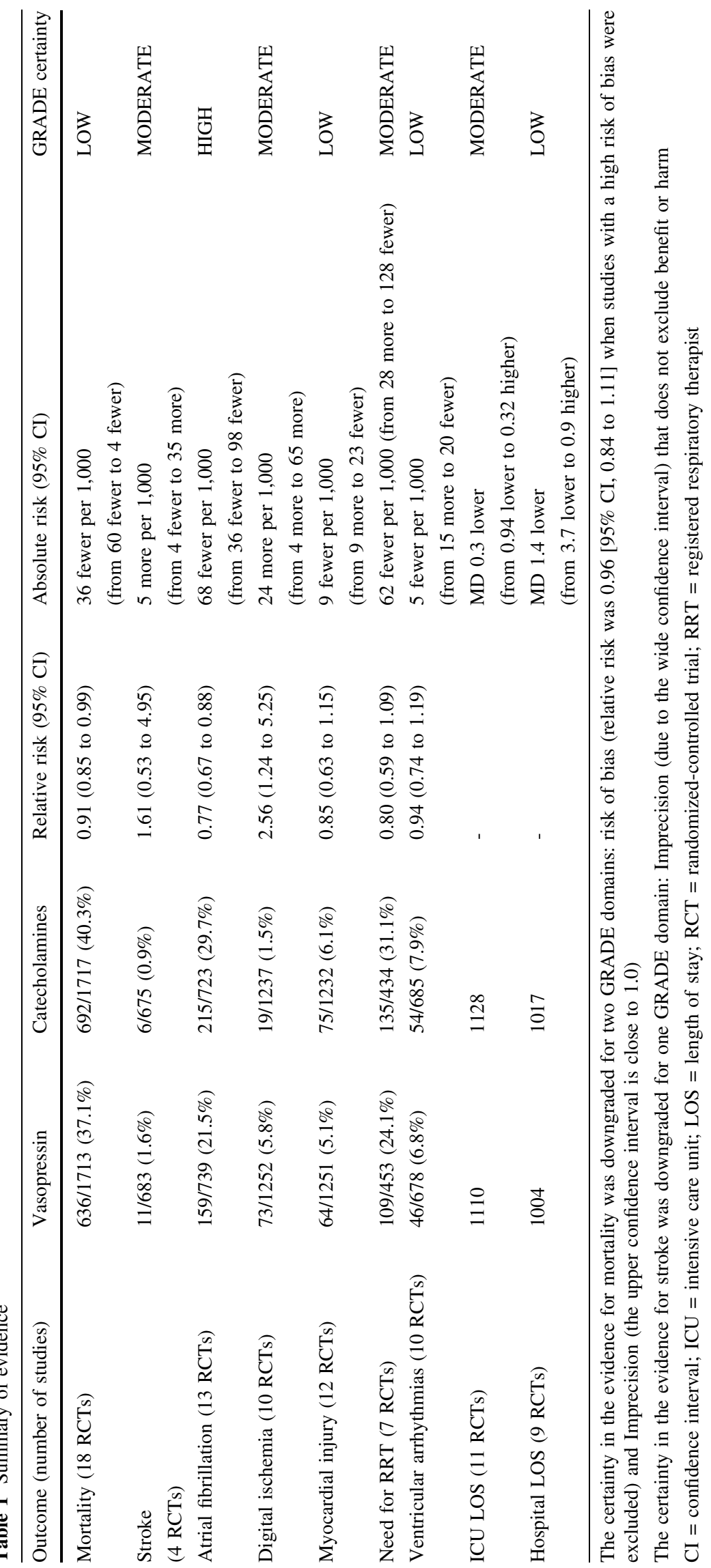


This recommendation takes into consideration the low certainty of mortality benefit (relative risk [RR], 0.91; 95\% confidence interval [CI], 0.85 to 0.99 ), the high certainty of atrial fibrillation risk reduction ( $\mathrm{RR}, 0.77$; $95 \% \mathrm{CI}, 0.67$ to 0.88 ), and the moderate certainty of risk increase in digital ischemia ( $R R, 2.56$; $95 \% \mathrm{CI}, 1.24$ to 5.25 ) with the addition of vasopressin or its analogues to catecholamines (Table, and ESM eFig. 2).

The panel placed a high value on the reduction in mortality, albeit there was low certainty in the evidence. Reviewing the evidence summary, the increased risk of atrial fibrillation with catecholamine therapy alone was mostly driven by the post-cardiac surgery population. ${ }^{30}$ As such, we conducted sensitivity analysis excluding the RCT by Hajjar et al., ${ }^{30}$ which demonstrated consistency in the finding of an increased risk of atrial fibrillation with catecholamine therapy alone (ESM eFig. 3). The panel agreed that new-onset atrial fibrillation has been associated with an increased incidence of stroke and mortality in this population. ${ }^{7}-9$ Although our meta-analysis did not find an increased risk of stroke with the use of catecholamines alone, this outcome was not systematically evaluated in the included studies.

The panel debated the relative importance of atrial fibrillation and digital ischemia from patients' perspectives. The panel agreed that individual patients are likely to attribute a variable level of importance to atrial fibrillation as an outcome. The panel's family partner opined that while atrial fibrillation and digital ischemia are both likely to be important outcomes from patients' perspectives, atrial fibrillation is likely of greater importance in this context because of its potential short-term (i.e., hemodynamic instability) and long-term (i.e., stroke, ${ }^{7}-{ }^{9}$ need for longterm therapy to control persistent atrial fibrillation and anticoagulation therapy for stroke prevention, and increased mortality) ${ }^{7}-9$ sequelae. The family partner and the other panel members also considered the heterogeneous or incomplete definition of digital ischemia (i.e., one study reported peripheral cyanosis, ${ }^{26}$ two others did not provide a definition, ${ }^{15,29}$ and none reported the occurrence of severe digital ischemia leading to digital necrosis, surgical intervention, or loss of limb function, which may be in part due to the absence of post-ICU follow-up). Weighing these potential benefits and harms, the panel opted for a conditional recommendation to add vasopressin to catecholamine vasopressors in the management of patients with distributive shock.

The average dosing of vasopressin and terlipressin in included studies and the associated forest plots are shown in ESM eTable 4 and eFig. 1. We have not made a recommendation regarding the dose of vasopressin and its analogues, as the included studies did not examine the impact of dosing regimens. Similarly, we have not made a specific recommendation regarding when to initiate vasopressin (i.e., at which dose of catecholamine therapy) as these data were not routinely reported in the included studies. Finally, we did not examine the specific subgroups that should receive vasopressin or its analogues in addition to catecholamines as subgroups were not systematically examined in the included studies.

There were no credible subgroup effects on the efficacy or safety of vasopressin based on cause of distributive shock (sepsis $v s$ vasoplegia following cardiac surgery). As such, our recommendation applies to all patients with distributive shock. A recent individual patient data metaanalysis (IPDMA) that included only four RCTs ( $n=1,453$ patients) examined the effect of vasopressin in patients with septic shock (the authors did not have access to individual patient data from the other relevant RCTs). ${ }^{42}$ This IPDMA found similar results to our meta-analysis, and demonstrated no credible subgroup effect of vasopressin based on time between onset of shock to initiation of vasopressin $(\leq 12 \mathrm{hr} v s>12 \mathrm{hr}$ ), shock severity based on vasopressor dose (norepinephrine dose $<$ $\left.15 \mu \mathrm{g} \cdot \min ^{-1} v s \geq 15 \mu \mathrm{g} \cdot \mathrm{min}^{-1}\right)$, shock severity based on baseline serum lactate level $\left(\leq 2 \mathrm{mmol} \cdot \mathrm{L}^{-1}\right.$ vs $>2$ mmol. $\mathrm{L}^{-1}$ ), or shock severity based on baseline renal function (according to RIFLE criteria). ${ }^{43,44}$ This IPDMA supports our recommendation to include all patients with distributive shock regardless of shock severity. Of note, this IPDMA found no difference in mesenteric ischemia between patients treated with or without vasopressin.

No published reports have examined the costeffectiveness of adding vasopressin to catecholamine vasopressors. Based on local cost data obtained by our panel, vasopressin is typically available at a similar cost to norepinephrine. The panel was confident that adding vasopressin to catecholamine vasopressors would be acceptable to patients, clinicians, and administrators, and be feasible to implement.

Several areas of uncertainty persist and deserve further investigation. First, the included studies did not examine several patient-important outcomes, such as functional independence, cognitive function, and quality of life, which were identified as critical outcomes by panel members (ESM eTable 1). Second, although digital ischemia may be a patient-important outcome, the severity and sequelae of this outcome is difficult to ascertain, especially in the context of the ambiguous descriptions of this outcome by included studies. In addition, although the evidence led the panel to provide a conditional recommendation for the addition of vasopressin to catecholamine vasopressors in the management of distributive shock, the optimal timing (or catecholamine dose) for vasopressin initiation remains uncertain. Finally, existing studies have not explored the effects of this intervention on specific patient subgroups 
such as those with reduced left ventricular ejection fraction.

Author contributions Bram Rochwerg chaired the guideline panel, helped to employ GRADE methodology and certainty of evidence assessments, and drafted the manuscript. Kimia Honarmand was the methods chair for the guideline panel and drafted the manuscript. Emilie Belley-Côté and Kevin Um led the systematic review team, and coordinated the evidence search and synthesis. All authors were panel members and contributed significantly to formulating the recommendation and providing edits to the manuscript.

\section{Conflicts of interest None declared.}

Funding statement Bram Rochwerg is supported by a Hamilton Health Sciences Early Career Research Award.

Editorial responsibility This submission was handled by Dr. Hilary P. Grocott, Editor-in-Chief, Canadian Journal of Anesthesia.

\section{References}

1. Lamontagne F, D'Aragon F, Burns KE, et al. Canadian Critical Care Society revised process for guideline development and endorsement. Can J Anesth 2018; 66: 1163-4.

2. Institute of Medicine (US) Committee on Standards for Developing Trustworthy Clinical Practice Guidelines; Graham $R$, Mancher M, Miller Wolman D, Greenfield S, Steinberg E. Clinical Practice Guidelines We Can Trust. Washington (DC): National Academies Press (US); 2011.

3. Landry DW, Oliver JA. The pathogenesis of vasodilatory shock. N Engl J Med 2001; 345: 588-95.

4. Gotts JE, Matthay MA. Sepsis: pathophysiology and clinical management. BMJ 2016; . https://doi.org/10.1136/bmj.i1585.

5. Rochwerg B, Hylands $M$, Moller $M$, et al. CCCS-SSAI WikiRecs Clinical Practice Guideline: vasopressor blood pressure targets in critically ill adults with hypotension. Can J Anesth 2017; 64: 7635.

6. McIntyre WF, Um KJ, Alhazzani W, et al. Association of vasopressin plus catecholamine vasopressors vs catecholamines alone with atrial fibrillation in patients with distributive shock: a systematic review and meta-analysis. JAMA 2018; 319: 1889900.

7. Wetterslev $M$, Haase $N$, Hassager $C$, et al. New-onset atrial fibrillation in adult critically ill patients: a scoping review. Intensive Care Med 2019; 45: 928-38.

8. Kim K, Yang PS, Jang E, et al. Long-Term impact of newly diagnosed atrial fibrillation during critical care: a South Korean nationwide cohort study. Chest 2019; 156: 518-28.

9. Walkey AJ, Wiener RS, Ghobrial JM, Curtis LH, Benjamin EJ. Incident stroke and mortality associated with new-onset atrial fibrillation in patients hospitalized with severe sepsis. JAMA 2011; 306: 2248-54.

10. Levy B, Fritz C, Tahon E, Jacquot A, Auchet T, Kimmoun A. Vasoplegia treatments: the past, the present, and the future. Crit Care 2018; . https://doi.org/10.1186/s13054-018-1967-3.

11. Ukor IF, Walley KR. Vasopressin in vasodilatory shock. Crit Care Clin 2019; 35: 247-61.

12. Russell JA. Bench-to-bedside review: Vasopressin in the management of septic shock. Crit Care 2011; . https://doi.org/ $10.1186 / \mathrm{cc} 8224$.
13. Rhodes A, Evans LE, Alhazzani W, et al. Surviving sepsis campaign: international guidelines for management of sepsis and septic shock: 2016. Intensive Care Med 2017; 43: 304-77.

14. Venkatesh B, Finfer S, Cohen J, et al. Adjunctive glucocorticoid therapy in patients with septic shock. N Engl J Med 2018; 378: 797-808.

15. Liu $Z M$, Chen J, Kou $Q$, et al. Terlipressin versus norepinephrine as infusion in patients with septic shock: a multicentre, randomised, double-blinded trial. Intensive Care Med 2018; 44: 1816-25.

16. Hammond DA, Ficek OA, Painter JT, et al. Prospective openlabel trial of early concomitant vasopressin and norepinephrine therapy versus initial norepinephrine monotherapy in septic shock. Pharmacol Drug Ther 2018; 38: 531-8.

17. Xiao $X$, Zhang J, Wang $Y$, et al. Effects of terlipressin on patients with sepsis via improving tissue blood flow. J Surg Res 2016; 200: 274-82.

18. Atkins $D$, Best $D$, Briss $P A$, et al. Grading quality of evidence and strength of recommendations. BMJ 2004; . https://doi.org/10. $1136 / \mathrm{bmj} .328 .7454 .1490$.

19. Alhazzani W, Lewis $K$, Jaeschke $R$, et al. Conflicts of interest disclosure forms and management in critical care clinical practice guidelines. Intensive Care Med 2018; 44: 1691-8.

20. Abdullah MH, Saleh SM, Morad WS. Terlipressin versus norepinephrine to counteract intraoperative paracentesis induced refractory hypotension in cirrhotic patients. Egyptia Journal of Anaesthesia 2012; 28: 29-35.

21. Acevedo JG, Fernandez J, Escorsell A, et al. Clinical efficacy and safety of terlipressin administration in cirrhotic patients with septic shock. J Hepatol 2009; . https://doi.org/10.1016/S01688278(09)60176-8.

22. Albanèse J, Leone $M$, Delmas A, Martin C. Terlipressin or norepinephrine in hyperdynamic septic shock: a prospective, randomized study. Crit Care Med 2005; 33: 1897-902.

23. Barzegar E, Ahmadi A, Mousavi S, Nouri M, Majtahedzadeh M. The therapeutic role of vasopressin on improving lactate clearance during and after vasogenic shock: microcirculation, is it the black box? Acta Med Iran 2016; 54: 15-23.

24. Capoletto C, Almeida J, Ferreira G, et al. Vasopressin versus norepinephrine for the management of septic shock in cancer patients (vancs ii). Crit Care 2017; 21(Suppl 1): 57 (abstract).

25. Chen Z, Zhou P, Lu Y, Yang C. Comparison of effect of norepinephrine and terlipressin on patients with ARDS combined with septic shock: a prospective single-blind randomized controlled trial (Chinese). Zhonghua Wei Zhong Bing Ji Jiu Yi Xue 2017; 29: 111-6.

26. Choudhury A, Kedarisetty CK, Vashishtha $C$, et al. A randomized trial comparing terlipressin and noradrenaline in patients with cirrhosis and septic shock. Liver Int 2017; 37: 552-61.

27. Dünser MW, Mayr AJ, Ulmer H, et al. Arginine vasopressin in advanced vasodilatory shock: a prospective, randomized, controlled study. Circulation 2003; 107: 2313-9.

28. Fonseca-Ruiz N, Lemos Cano A, Ortiz Carmona DP, et al. Uso de vasopresina en pacientes con choque séptico refractario a catecolaminas (Spanish). Acta Colombiana de Cuidado Intensivo 2013; 13: 114-23.

29. Gordon AC, Mason AJ, Thirunavukkarasu N, et al. Effect of early vasopressin vs norepinephrine on kidney failure in patients with septic shock: the VANISH randomized clinical trial. JAMA 2016; 316: 509-18.

30. Hajjar LA, Vincent JL, Barbosa Gomes Galas FR, et al. Vasopressin versus norepinephrine in patients with vasoplegic shock after cardiac surgery: the VANCS randomized controlled trial. Anesthesiology 2017; 126: 85-93.

31. Han $X$, Sun H, Huang $X Y$, et al. A clinical study of pituitrin versus norepinephrine in the treatment of patients with septic 
shock (Chinese). Zhongguo Wei Zhong Bing Ji Jiu Yi Xue 2012; 24: 33-7.

32. Hua F, Wang $X$, Zhu $L$. Terlipressin decreases vascular endothelial growth factor expression and improves oxygenation in patients with acute respiratory distress syndrome and shock. $\mathbf{J}$ Emerg Med 2013; 44: 434-9.

33. Lauzier $F$, Lévy $B$, Lamarre $P$, Lesur $O$. Vasopressin or norepinephrine in early hyperdynamic septic shock: a randomized clinical trial. Intensive Care Med 2006; 32: 1782-9.

34. Malay MB, Ashton RC Jr, Landry DW, Townsend RN. Low-dose vasopressin in the treatment of vasodilatory septic shock. J Trauma 1999; 47: 699-803; discussion 703-5.

35. Morelli A, Ertmer C, Rehberg $S$, et al. Continuous terlipressin versus vasopressin infusion in septic shock (TERLIVAP): a randomized, controlled pilot study. Crit Care 2009; . https://doi. org/10.1186/cc7990.

36. Oliveira $S$, Dessa $F$, Rocha $C$, Oliveira $F$. Early vasopressin application in shock study. Crit Care 2014; . https://doi.org/10. 1186/cc13348.

37. Patel BM, Chittock DR, Russell JA, Walley KR. Beneficial effects of short-term vasopressin infusion during severe septic shock. Anesthesiology 2002; 96: 576-82.

38. Prakash V, Choudhury AK, Sarin SK. Early introduction of a combination of low dose terlipressin and noradrenaline as vasopressors is superior to high dose noradrenaline alone in patients of cirrhosis with septic shock (NCT02468063). Hepatology 2017; 138A (abstract).
39. Russell JA, Walley KR, Singer J, et al. Vasopressin versus norepinephrine infusion in patients with septic shock. N Engl $J$ Med 2008; 358: 877-87.

40. Svoboda P, Scheer P, Kantorová I, et al. Terlipressin in the treatment of late phase catecholamine-resistant septic shock. Hepatogastroenterology 2012; 59: 1043-7.

41. Russell JA, Vincent JL, Kjolbye AL, et al. Selepressin, a novel selective vasopressin $\mathrm{V}_{1 \mathrm{~A}}$ agonist, is an effective substitute for norepinephrine in a phase IIa randomized, placebo-controlled trial in septic shock patients. Crit Care 2017; . https://doi.org/10. 1186/s13054-017-1798-7.

42. Nagendran M, Russell JA, Walley KR, et al. Vasopressin in septic shock: an individual patient data meta-analysis of randomised controlled trials. Intensive Care Med 2019; 45: 844-55.

43. Mehta RL, Kellum JA, Shah SV, et al. Acute Kidney Injury Network: report of an initiative to improve outcomes in acute kidney injury. Crit Care 2007; . https://doi.org/10.1186/cc5713.

44. Bellomo R, Ronco C, Mehta RL, et al. Acute kidney injury in the ICU: from injury to recovery: reports from the 5th Paris International Conference. Ann Intensive Care 2017; . https:// doi.org/10.1186/s13613-017-0260-y.

Publisher's Note Springer Nature remains neutral with regard to jurisdictional claims in published maps and institutional affiliations. 